Ambient Science, 2020: Vol. 07(Sp1); 20-27

DOI:10.21276/ambi.2020.07.sp1.0a02

\title{
The Effect of Using Virtual Reality Headseton Dynamic Balance and Reaction Time of Handball Players
}

\section{Inci Kesilmiș}

Department of Physical Education and Sports, OsmaniyeKorkut Ata University, Osmaniye, Turkey

Study Area: Osmaniye, Turkey

Coordinates: $37^{\circ} 04^{\prime} 30$ ? $\mathrm{N}_{3} 6^{\circ}{ }^{1}{ }^{\prime} \mathrm{oo}$ ? E

Key words: Sport training, Sensoriomotor, Sports techniques, Sports skill

\section{Abstract}

The aim of this research is to examine the effects of games played with VR hood and handball training on dynamic balance and reaction time. A randomized pretest and posttest control study. 70 women in the 11-14 age group were randomly divided into three groups after pretesting measurements. The first group was the Handball-VR Group, the second group was the Handball Group and the third group was determined as the Control Group. In addition to handball training, HVRG played with the VR game console 30 minutes during 3 days a week for 8 weeks. HG participated in Handball training sessions that lasted 1.5 hours a day, three days a week for only 8 weeks. CG did not participate in any sports activities. After 8 weeks of completion, post-test measurements were made. Dynamic balance measurements were made with Prokin Tecno Body PK20o and reaction time measurements with Fitlight Trainer. Dynamic balance posttest success order is HVRG, HG and CG. When the pre-post test differences are examined, the observed balance differences of the HVRG and $\mathrm{HG}$ groups are statistically significant and are in favor of the post-test. The reaction differences observed for HVRG and $\mathrm{HG}$ are statistically significant and favor the post-test. For CG, no difference was observed between the pre-post test. The HVRG group succeeded as compared to the other two groups on the basis of reaction time, movement time and lights missed. Conclusively, the VR program applied in addition to handball training effectively improves balance ability and reaction time that are extremely necessary for both handball and daily life activities.

different types of movements, such as forward, backward, side movements, and swirling. (Michalsik et al., 2013; Wurm, 2020). In the handball game, the perception of the ball before the opponent allows the response to be given 40-50 milliseconds before, and therefore, to act before the opponent's action. Performance depends on the ability to react correctly under time pressure, and response formation takes several milliseconds, it is important to be in the right place at the right time (Kulpa et al., 2013). The reaction time, which is important for the development of sports performance, is def ined as the measure of the time between the reception of an stimulus and the initiation of the motor response (C,atiktas, et al., 2011). Competition players exposed to a lot of visual stimuli, in high-speed struggles,

*Author: incikesilmis@osmaniye.edu.tr 
shows that the reaction time is a necessity in athletes, and the balance process is based on integrating information from visual (C,aiktas, et al., 2011), vestibular and proprioceptive systems to elicit appropriate muscle responses to produce postural corrections during the sports involvement of the body's center of gravity (Mickle et al., 2011). Balance is an integral component of all functional movement activities.

With the development of technology, new approaches are added to training methods, and the use of technological equipment is increasing, which affects the development of small but successful details for the athlete. Even in team sports, the importance of individual training is gradually increasing, and the studies carried out in this context support the fact that software that can provide VR to the athlete can be used for training in the near future (Boot et al., 2017; Van Diest et al., 2016). Simulation-based individual training is promising and is recognized as a means of improving the efficiency of training (Hancock, 2009). VR refers to a computer simulated environment that aims to evoke the feeling of being mentally or physically elsewhere. VR interventions need to ensure that the sports environment is created in a realistic way. What matters to a sports-themed VR device is that a complex environment is presented as an accurate physics model, real-time response detection and functionally high accuracy. In this direction, VR scenarios offer multiple scenarios to players of different difficulty levels and it is aimed to gain advanced skills that can be applied directly to the real sports arena (Miles et al., 2012). Studies in the literature have reached the conclusion that VR interventions offer a unique standardized environment for analyzing perception-action coupling in handball (Bideau et al., 2004), rugby (Brault et al., 2010) and football (Craig et al., 2009). However, studies in the literature are limited with this method, which has been newly used in a sportive sense. Work on handball is usually done on goalkeepers (Bideau et al., 2004; Bideau et al.,2003; Bolte et al., 2010).

Studies are available in the literaure comparing the reaction time of expert and novice athletes in soccer players of VR intervention (Savelsbergh et al., 2002), perfprming VR interventions in expert and novice tennis players and although the experts are faster than the novices, in which no difference was observed in the accuracy of the results between the groups (Williams et al., 2002), reaching the conclusion that VR interventions improve cerebral palsy population reaction time (Pourazar et al., 2017), and reporting that VR game-based education is better than realworld tasks in improving balance and functional performance in paraplegic individuals (Khurana et al., 2017). Meanwhile, it is important that VR interventions can make a difference on motoric features in addition to training. In line with this information, the main purpose of this research is to investigate the effect of VR hood and handball training on dynamic balance and reaction time. The hypothesis of the research is that handball training can improve the dynamic balance and reaction time, but VR training applied in addition to handball training may lead to a more effective development.

\section{Materials and Methods:}

This is a randomized pretest posttest control group study. Participants were first pretested and randomly divided into three groups. None of the participants have played handball before the study. The first group was determined as the handball-VR group (HVRG, $\mathrm{n}=25$ ). Participants in this group participated in basic handball training, which lasted 1.5 hours a day, three days a week for 8 weeks, and additionally played games with the Sony Play Station 4 game console 3 days a week for 30 minutes. The second group was determined as handball group $(\mathrm{HG}, \mathrm{n}=25)$. The handball group participated in basic handball training, which lasted 1.5 hours a day, three days a week for just 8 weeks. The third group was designated as the control group $(C G, n=20)$ and was formed only from the participants who did not participate in any sports activities. After the pretest measurements were made, the groups were randomly divided into three groups and started HVRG and HG training. After the 8-week training period was completed, post-test measurements were made. Ethics Approval Certificate was obtained from Osmaniye Korkut Ata University Scientific Research Unit and Publication Ethics Committee before the research started (59754796-050.99 / 21-7). In addition, the "Informed Consent Form" prepared according to Helsinki criteria was signed to the parents of all participants who volunteered to participate in the research.

The study was conducted with 70 female participants in the 11-14 age group. Twenty-five female participants in HVRG (age $13 \pm 0.81$ years; weight $44.64 \pm 6.76 \mathrm{~kg}$; stature $152.08 \pm 7.44 \mathrm{~cm}$ ), twenty-five female in HG (age $12.84 \pm 0.85$ years; weight $45.89 \pm 11.26 \mathrm{~kg}$; stature $151.18 \pm 7.44 \mathrm{~cm}$ ) and twenty female in CG (age 13.05 \pm 0.94 years; weight $42.50 \pm$ $3.42 \mathrm{~kg}$; stature $150.45 \pm 4.26 \mathrm{~cm}$ ) take part in the study. Before collecting data, all of the participants performed 10 minutes of warm-up, including lower extremities static stretching exercises (calf, quadriceps, hamstrings, hip flexors, illiotibial band/lower back). Stretching consisted of 3 sets of 30 seconds each (Hewett et al., 1999).

Balance measurements were performed with Prokin PK20o [Tecno Body] balance measurement device on double-right-left foot for 30 seconds. In the system consisting of a mobile platform and computer software, the participant goes over the device to see the screen of the computer and after maintaining hands-free balance, he/she tries to maintain her balance in the center of the circular shape displayed on the screen in line with the software. If the participant falls on the instrument or descends before the time expires, the measurement is repeated. Before the test started, the participants 
performed two trials to adapt to the test. After the test started, each participant made three interventions. Of the three interventions, the best practice is used for statistical analysis (Mauch \& Kälin, 2011).

In our study, the simple reaction time, defined as the elapsed time between a single perceived alert and a single response, was measured. The reason why the simple reaction time is usually short is due to the absence of another warning for the individual and also no other response it should give. In addition, evaluation of simple reactions by the central nervous system occurs faster than complex reactions (Deepa et al., 2016; Pancar \& Ark., 2016). In order to determine the reaction time, Fitlight Trainer System was used. The system is a reaction development and training system that is completely wireless and consisting of 8 laser led light transmitters and a tablet-like central hand control unit. These 8 laser lights are used to activate or deactivate with the movements of the athlete. Various measurements related to the performance of the athlete can be made simultaneously or recorded on the tablet for comparison and analysis in the future. In order to collect data, participants were asked to turn out 6 LED lights placed in circular points on the floor in random order as quickly as possible with their feet. After displaying 13 LEDs, the scores of the participants were recorded as total time (movement time) in seconds (sec), average light extinguishing time (reaction time) and missed lights. If the led light in the protocol turns off automatically after 4 seconds of standby time, it is saved as a missed led. Before the test started, two attempts were made for the participant to adapt. After the test started, the measurements were repeated twice and the better measurement for statistical analysis was taken into consideration. Therefore, three results are obtained as reaction time, motion time and missed lights.

Handball training was performed for HVRG and HG for 8 weeks, 3 days a week, 1.5 hours a day. Training studies consist of conditioning, throwing-holding, passing exercises, dribbling, basic shooting, bouncing and anklepass exercises, jumping shot, double triple motion rust resurrection, collective offensive and defensive exercises, block shots, wing shots, 7 meter throw, pivot playing resurrections, moving passes and shooting exercises, threeto-three offense training, offensive man offense training, deception training, 3-2-1 defense, block top and wing, transition from 3-2-1 defense to 6-o defense, transition from 6-o defense to 3-2-1 defense, combinations of offense and defense, transition from playmaker to double pivot, defense against man, offensive with missing man.

Super Amaze Balls and Holo Ball games were preferred for VR training. Each participant in the HVRG group played the games limited to 30 minutes a day, three days a week in addition to handball training for 8 weeks. The Super Amaze Balls game, that is suitable for over 12 years old, is played using both hands of the participant by turning the platform, tilting and rotating a multi-axis platform similar to the pinball game. The game has leader boards and supports the competitive environment. The Holo Ball game is a retro future-themed game directed by artificial intelligence, involving struggle in the world, by hitting the racket to score points, hitting and spinning, and all the balls are tried to be passed behind the opponent and the difficulty level increases as played.

All statistical analysis was performed by using IBM SPSS 22 package (SPSS Inc, Chicago, IL). Kolmogorov Smirnov test used to check normal distribution assumptions. Statistical significance was set at $\mathrm{p}<.05$. Since the distribution was not normal, for inter-group comparisons the Kruskall Wallis $\mathrm{H}$ test, for analysis of the difference between groups the Mann-Whitney U test, for pre-test / post-test comparisons the Wilcoxon signed-rank test, and finally for categorical variables the Chi-Square analysis were applied, respectively.

\section{Results:}

No statistically significant difference was observed in the pretest measurements applied to all participants ( $\mathrm{p}>$ $.05)$. Accordingly, the groups were randomly divided into three groups and the training started. The participation rate of the HVRG and HG groups in the training period is $100 \%$. The control group did not participate in any sports activities. Demographic characteristics did not differ between the groups ( $p>0.05$ ). The mean and standard deviation of the participants' descriptive data of all variables are presented in Table 1.

\begin{tabular}{llll}
\multicolumn{4}{c}{ Table 1. Posttest dynamic balance and reaction time mean and } \\
\multicolumn{4}{c}{ standard deviation values of all groups } \\
\hline Variables & HVRG $(\mathrm{n}=25)$ & HG $(\mathrm{n}=25)$ & $\mathrm{CG}(\mathrm{n}=20)$ \\
& Mean $\pm \mathrm{SD}$ & Mean $\pm \mathrm{SD}$ & Mean $\pm \mathrm{SD}$ \\
BPL & $345.36 \pm 105.17$ & $381.67 \pm 70.51$ & $491.50 \pm 99.67$ \\
RPL & $204.09 \pm 69.21$ & $281.77 \pm 121.19$ & $302.56 \pm 81.11$ \\
LPL & $\mathbf{2 2 6 . 2 2 \pm 8 1 . 5 0}$ & $301.43 \pm 147.88$ & $318.87 \pm 87.96$ \\
ART & $0.64 \pm 0.07$ & $0.74 \pm 0.11$ & $0.74 \pm 0.08$ \\
MT & $32.24 \pm 3.35$ & $33.22 \pm 2.06$ & $41.11 \pm 8.21$ \\
\hline
\end{tabular}

BPL= Bipedal Perimeter Length; RPL= Right Perimeter Length; LPL=Left Perimeter Length; ART=Average Reaction Time; MT=Movement Time

When Table 1 is examined, the HVRG group reaches the most successful average values for the dynamic balance variable, followed by HG and CG.

When the differences between the pretest-posttest measurements of the three groups were examined, statistically significant differences were observed in all variables except movement time in the HVRG and HG group ( $\mathrm{p}<0.05)$. In the control group, only the difference in movement time was observed ( $\mathrm{p}<0.05)$.

When the differences between the pretest-posttest measurements of the three groups were examined, statistically significant differences were observed in all 
Table-2: Table-2: Differences between the pretest-posttest dynamic balance and reaction time values of all groups

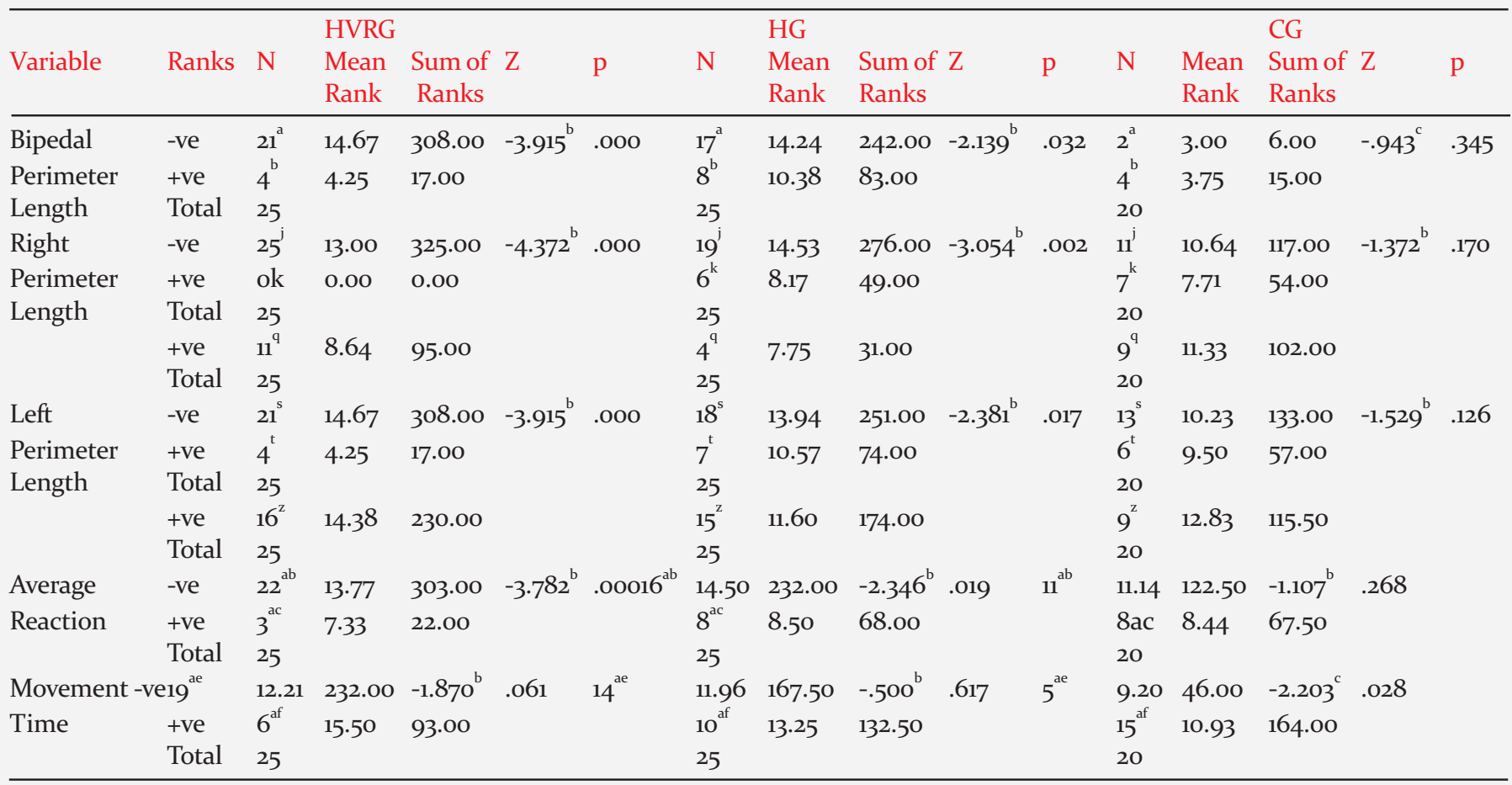

variables except movement time in the HVRG and HG group $(\mathrm{p}<0.05)$. In the control group, only the difference in movement time was observed $(\mathrm{p}<0.05)$.

Table-3: Differences after intervention between three groups

\begin{tabular}{|c|c|c|c|c|c|c|}
\hline Groups & $\mathrm{N}$ & $\begin{array}{l}\text { Me } \\
\text { Rar }\end{array}$ & & $\begin{array}{l}\text { Kruskal } \\
\text { Wallis H }\end{array}$ & $\mathrm{df}$ & $\mathrm{p}$ \\
\hline $\begin{array}{l}\text { Bipedal } \\
\text { Perimeter } \\
\text { Length }\end{array}$ & $\begin{array}{l}\text { HVRG } \\
\text { HG } \\
\text { CG }\end{array}$ & $\begin{array}{l}25 \\
25 \\
20\end{array}$ & $\begin{array}{l}24.48 \\
32.84 \\
52.60\end{array}$ & 21.878 & 2 & $.00{ }^{*}$ \\
\hline $\begin{array}{l}\text { Right } \\
\text { Perimeter } \\
\text { Length }\end{array}$ & $\begin{array}{l}\text { HVRG } \\
\text { HG } \\
\text { CG }\end{array}$ & $\begin{array}{l}25 \\
25 \\
20\end{array}$ & $\begin{array}{l}24.62 \\
38.30 \\
45.60\end{array}$ & 12.545 & 2 & $.002^{*}$ \\
\hline $\begin{array}{l}\text { Left } \\
\text { Perimeter } \\
\text { Length }\end{array}$ & $\begin{array}{l}\text { HVRG } \\
\text { HG } \\
\text { CG }\end{array}$ & $\begin{array}{l}25 \\
25 \\
20\end{array}$ & $\begin{array}{l}26.46 \\
36.94 \\
45.00\end{array}$ & $9 \cdot 417$ & 2 & $.009^{*}$ \\
\hline $\begin{array}{l}\text { Average } \\
\text { Reaction } \\
\text { Time }\end{array}$ & $\begin{array}{l}\text { HVRG } \\
\text { HG } \\
\text { CG }\end{array}$ & $\begin{array}{l}25 \\
25 \\
20\end{array}$ & $\begin{array}{l}22.26 \\
42.60 \\
43.18\end{array}$ & 16.492 & 2 & $.000^{*}$ \\
\hline $\begin{array}{l}\text { Movement } \\
\text { Time }\end{array}$ & $\begin{array}{l}\text { HVRG } \\
\text { HG } \\
\text { CG }\end{array}$ & $\begin{array}{l}25 \\
25 \\
20\end{array}$ & $\begin{array}{l}23.84 \\
33.28 \\
52.85\end{array}$ & $23.040 \quad 2$ & $.000^{*}$ & \\
\hline
\end{tabular}

As per Kruskal Wallis $\mathrm{H}$ test analysis results applied to the pretest data for all measurements, all groups were initially statistically insignificant. The results of posttest Kruskal Wallis H Test analysis of balance and reaction time measurements are given in Table.3. Analysis results show that, bipedal perimeter length $\left[\chi^{2}(\mathrm{sd}=2, \mathrm{n}=70)=21.878, \mathrm{p}\right.$ $<.05]$, right perimeter length [2 $(\mathrm{sd}=2, \mathrm{n}=70)=12.545, \mathrm{p}$ between groups $<.05]$, left perimeter length $\left[\chi^{2}(\mathrm{sd}=2, \mathrm{n}=\right.$ $7 \mathrm{o})=9.417, \mathrm{p}<.05]$, average reaction time $\left[\chi^{2}(\mathrm{sd}=2, \mathrm{n}=7 \mathrm{O})=\right.$
16.492, $\mathrm{p}<.05]$ movement time $\left[\chi^{2}(\mathrm{sd}=2, \mathrm{n}=70)=23.040, \mathrm{p}\right.$ $<.05$ ] results differ significantly. These findings show that VR and handball training have different effects on the participants' dynamic balance and reaction time. Considering the rank averages, the success order for doubleright-left dynamic balance and average reaction time and movement time variable are HVRG, HG and CG.

The source of the difference was examined by applying the Mann Whitney U test to determine the significant difference observed between the groups depending on the significant differences between the groups (Table 3-4-5).

Table-4: Differences after intervention between HVRG \& HG groups

Variables Groups N Mean Sum of $\begin{aligned} & \text { Mann- } \\ & \text { Whit. } U\end{aligned}$ Asym.

Whit. U Sig.

Bipedal HVRG $25 \quad 21.28 \quad 532.00 \quad 207.000-2.047 \quad 0.041^{*}$

Perimet. Lt. HG $25 \quad 29.72 \quad 743.00$

$\begin{array}{llllllll}\text { Right HVRG } & 25 & 20.58 & 514.50 & 189.500 & -2.387 & 0.017^{*}\end{array}$

Perimet. Lt. HG $25 \quad 30.42 \quad 760.50$

$\begin{array}{llllllll}\text { Left } & \text { HVRG } & 25 & \mathbf{2 2 . 3 4} & 558.50 & 233.500 & \mathbf{1} .533 & 0.125\end{array}$

Perimet. Lt. HG $25 \quad 28.66 \quad 716.50$

$\begin{array}{lllllll}\text { Average HVRG } 25 & 18.46 & 461.50 & 136.500 & -3.419 & 0.001\end{array}$

$\begin{array}{llll}\text { React. Time HG } & 25 & 32.54 & 813.50\end{array}$

Movement HVRG $25 \quad 21.32 \quad 533.00 \quad 208.000-2.028$ o.043*

$\begin{array}{lllll}\text { Time } & \text { HG } & 25 & 29.68 & 742.00\end{array}$

When the Mann Whitney $U$ test results of the participants with HVRG and HG were examined, Bipedal Perimeter Length $(U=207.0, p<.05)$, right perimeter length $(U=189.5, p<.05)$, average reaction time $(U=136.5, p<.05)$, movement time $(U=208, p<.05)$ results showed significant 


\section{ORIGINAL ARTICLE}

differences. Considering the rank averages, it is seen that HVRG test results are more successful. This finding shows that VR training is effective in improving double and right foot balance and reaction time (Table 4)

Table-5: Differences after intervention between HVRG and CG groups

\begin{tabular}{|c|c|c|c|c|c|c|c|}
\hline Variables & Groups & $\mathrm{N}$ & Mean & Sum of & $\begin{array}{l}\text { Mann- } \\
\text { Whit. U }\end{array}$ & Z & $\begin{array}{l}\text { Asym. } \\
\text { Sig. } \\
\text { 2-tail. }\end{array}$ \\
\hline Bipedal & HVRG & 25 & 16.20 & 405.00 & 80.000 & -3.883 & $0.000^{*}$ \\
\hline Perimet. Lt. & $\mathrm{HG}$ & 20 & 31.50 & 630.00 & & & \\
\hline Right & HVRG & 25 & 17.04 & 426.00 & 101.000 & -3.404 & $0.001^{*}$ \\
\hline Perimet. Lt. & $\mathrm{HG}$ & 20 & 30.45 & 609.00 & & & \\
\hline Left & HVRG & 25 & 17.12 & 428.00 & 103.000 & -3.358 & $0.001^{*}$ \\
\hline Perimet. Lt. & HG & 20 & 30.35 & 607.00 & & & \\
\hline Average & HVRG & 25 & 16.80 & 420.00 & 95.000 & -3.544 & $0.000^{*}$ \\
\hline React. Time & HG & 20 & 30.75 & 615.00 & & & \\
\hline Movement & HVRG & 25 & $15 \cdot 5^{2}$ & 388.00 & 63.000 & -4.271 & $0.000^{*}$ \\
\hline Time & $\mathrm{HG}$ & 20 & 32.35 & 647.00 & & & \\
\hline
\end{tabular}

When the results of Mann Whitney $U$ test of the participants with HVRG and CG were examined, significant differences were observed between Bipedal Perimeter Length $(U=80.0, p<.05)$, right perimeter length $(U=101.0$, $\mathrm{p}<.05)$, left perimeter length $(\mathrm{U}=103.0, \mathrm{p}<.05)$ the average reaction time $(\mathrm{U}=95.0, \mathrm{p}<.05)$ and movement time $(\mathrm{U}=$ 63.0, $\mathrm{p}<.05)$ results. Considering the rank averages, it is seen that HVRG test results are more successful compared to CG. This finding shows that VR and handball training are effective in improving balance and reaction time (Table 5).

Table-6: Differences after intervention between HG \& CG groups

\begin{tabular}{|c|c|c|c|c|c|c|c|}
\hline Variables & Groups & $\mathrm{N}$ & Mean & Sum of & $\begin{array}{l}\text { Mann-- } \\
\text { Whit. U }\end{array}$ & Z & $\begin{array}{l}\text { Asym. } \\
\text { Sig. } \\
\text { 2-tail. }\end{array}$ \\
\hline Bipedal & HVRG & 25 & 16.12 & 403.00 & 78.000 & -3.929 & $0.000^{*}$ \\
\hline Perimet. Lt. & $\mathrm{HG}$ & 20 & 31.60 & 632.00 & & & \\
\hline Right & HVRG & 25 & 20.88 & 522.00 & 197.000 & -1.211 & 0.226 \\
\hline Perimet. Lt. & $\mathrm{HG}$ & 20 & 25.65 & 513.00 & & & \\
\hline Left & HVRG & 25 & 21.28 & 532.00 & 207.000 & -0.982 & 0.326 \\
\hline Perimet. Lt. & $\mathrm{HG}$ & 20 & 25.15 & 503.00 & & & \\
\hline Average & HVRG & 25 & 23.06 & 576.50 & 248.500 & -0.034 & 0.973 \\
\hline React. Time & $\mathrm{HG}$ & 20 & 22.93 & 458.50 & & & \\
\hline Movement & HVRG & 25 & 16.60 & 415.00 & 90.000 & -3.655 & $0.000^{*}$ \\
\hline Time & HG & 20 & 31.00 & 620.00 & & & \\
\hline
\end{tabular}

When the Mann Whitney $U$ test results of the participants with HG and CG were examined, significant differences were observed between the Bipedal Perimeter Length $(U=78.0, p<.05)$ and movement time $(U=90.0, p$ $<.05)$ results. Considering the mean ranks for these two variables, it is seen that HG test results are more successful compared to CG. This finding shows that handball training is effective in improving bipedal balance and total reaction time (Table 6).

According to the results of Chi-Square, the most successful group is HVRG group when the number of lights
Ambient Science, 2020: Vol. 07(Sp1); 20-27 DOI:10.21276/ambi.2020.07.sp1.oa02

that cannot be extinguished in the reaction time test of the HVRG group at the end of the 8-week training period $\left(\chi^{2}\right.$ $=11.840, p<.05) .15$ participants did not miss any light. The HVRG group is followed by the HG and CG groups (Table 7).

Table-7: Reaction time missed light Chi-Square analyse results Groups Missed Light Observed N Expected N Residual-Square

\begin{tabular}{|c|c|c|c|c|c|c|c|}
\hline \multirow{2}{*}{$\begin{array}{l}\text { Groups } \\
\text { HVRG }\end{array}$} & \multirow{2}{*}{$\begin{array}{l}\text { Missed } \\
\text { Light }\end{array}$} & \multirow{2}{*}{$\begin{array}{l}\text { Obs. } \\
\mathrm{N} \\
15\end{array}$} & \multirow{2}{*}{$\begin{array}{l}\text { Exp. } \\
\mathrm{N} \\
8.3\end{array}$} & \multicolumn{3}{|c|}{ Residual Chi-Square df } & \multirow{2}{*}{$\begin{array}{l}\text { Asymp. } \\
\text { Sig. } \\
.003\end{array}$} \\
\hline & & & & 6.7 & $11.840 a$ & 2 & \\
\hline & 1.00 & 9 & 8.3 & .7 & & & \\
\hline & 2.00 & 1 & 8.3 & $-7 \cdot 3$ & & & \\
\hline & Total & 25 & & & & & \\
\hline \multirow[t]{5}{*}{ HG } & .00 & 11 & 6.3 & 4.8 & $10.040 \mathrm{~b}$ & 3 & .018 \\
\hline & 1.00 & 9 & 6.3 & 2.8 & & & \\
\hline & 2.00 & 4 & 6.3 & -2.3 & & & \\
\hline & Total & 25 & & & & & \\
\hline & 3.00 & 1 & 6.3 & $-5 \cdot 3$ & & & \\
\hline \multirow[t]{6}{*}{ CG } & .00 & 8 & 4.0 & 4.0 & $9 \cdot 500 \mathrm{C}$ & 4 & .050 \\
\hline & 1.00 & 6 & 4.0 & 2.0 & & & \\
\hline & 2.00 & 4 & 4.0 & 0.0 & & & \\
\hline & Total & 20 & & & & & \\
\hline & 5.00 & 1 & 4.0 & -3.0 & & & \\
\hline & 6.00 & 1 & 4.0 & -3.0 & & & \\
\hline
\end{tabular}

\section{Discussion:}

The aim of this research is to examine the effect of VR game program, which is applied in addition to handball training, on dynamic balance and reaction time. The results of this study showed that eight weeks of VR and handball exercises significantly improved the performance in the dynamic balance and reaction time. The success order for doubleright-left foot dynamic balance variable is HVRG, HG and CG. In our study, when the pretest-posttest differences for the dynamic balance variable were examined, the balance differences observed for the double-right and left feet of the HVRG and HG groups were statistically significant and were in favor of the post-test. Double and right foot balance values of HVRG group and its double right and left balance values are statistically different from HG and CG group, respectively. This difference is in favor of the HVRG group in all variables $(\mathrm{p}<0.05)$. The differences observed between the HG and CG group are statistically significant only in terms of double foot balance values. Therefore, considering the balance variable differences in our research, the importance of the effect of participation in VR games applied in addition to handball training is clearly observed. As a developing and widespread technology, VR interventions have become increasingly popular in use for developing balance (Laufer et al., 2014). Balance training performed by using VR is an advantageous and ideal tool (Holden, 2005), compared to traditional training, also offers increased feedback on performance individually, and stimulates both motor and cognitive processes, as it offers increased feedback on visual, vestibular and somatosensory input and performance (Dockx et al., 2013; Taylor et al., 2011). It has been reported that VR 
interventions can activate the cerebral cortex, improve the spatial orientation capacity of the person, thereby improving the ability of the cortex to control balance (Mao et al., 2014). Horlings et al. (2009) confirmed that balance exercises performed with VR can provide more realistic proprioceptive and visual input and reported that the participant effectively improved the reaction time, postural stability, balance and walking function. Keshner (2004) investigates that VR technology can improve our ability to affect the nervous system, reports that VR interventions are successful in enhancing postural stability. In a review study performed by Porras et al. (2018), where they aim to reveal the advantages of VR in the rehabilitation of balance and walking, they have reported VR interventions to improve balance in all cohorts, especially when combined with traditional rehabilitation. However, studies are generally related to the post-disability rehabilitation process or to reduce the symptoms of neurological diseases. In another study on handball players, Gioftsidou et al. (2012) reported that balance training improved all balance performance indicators of the participants in the experimental group. Bideau et al. (2003) compared the handball shooters in virtual and real environments, they have reported that the virtual environment offers enough realism to reveal natural movements and that handball players are found to be interested in participating virtual training. Our research findings are compatible with the literature.

In our study, when the pretest-posttest differences for the average reaction time variable were examined, the reaction differences observed for the HVRG and HG groups were statistically significant and favored the posttest. For CG, no difference was observed between the pre-test and the post-test. For Movement time variable, only difference was observed for CG group. Considering the number of lights that cannot be extinguished in the reaction time test, the most successful group is the HVRG group. A total of 15 participants did not miss any light (Table-7). HVRG group is followed by HG and CG groups. The differences between the groups are statistically significant $(\mathrm{p}<0.05)$. Although the processes that affect the reaction time success are not directly observable, the reaction time is an indication of a person's decision-making velocity; however, it is not taken into account whether the decision is correct or appropriate (Haibach et al., 2011). It is desirable that the reaction is correct and fast. According to the results we obtained from our research findings, the HVRG group achieved successful results in terms of reaction time, movement time and missed lights compared to the other two groups and these results are statistically significant. Although the $\mathrm{HG}$ group does not differ from the CG group in the reaction time variable, the observed differences for movement time are statistically significant and are in favor of HG. Similar to our research, there are studies reporting that athletes have better reaction time than sedentary ones (Moka et al., 1992;
Nakamoto \& Mori 2008). Ghuntla et al. (2012) have revealed that basketball players' simple visual reaction times are significantly faster than sedentary. Nakamoto \& Mori (2008) in the study examining the motor skills of baseball and basketball players and sedentary; have shown that the reaction times of athletes are faster than those who lead a sedentary life. Rival et al. (2003), in the study where they examined the effect of spatial and temporal accuracy instructions, reported that the reaction time was slower, when children are instructed to move to a light-lit target as accurately and as quickly as possible, or when they are instructed to focus on both speed and accuracy. However, in our research, HVRG group achieved both correct and rapid results in line with the directives given for correct and fast action. This may be a positive effect of VR training applied to the HVRG group. In the literature, it has been revealed that playing games with technological tools increase the spatialspatial perception skill adequacy (Latham et al., 2013). Similar to our research, there are studies that conclude that participants who play computer-based games obtain faster reaction time data than those who do not play games (Chiang et al., 2012; Lee \& Peng, 2006). This was explained by Green \& Bavelier (2011) that the participants playing computer games had better reaction time since they could produce a more effective stimulus-response map compared to those who did not. Romeas et al. (2016) showed that there was a significant increase in the decision-making accuracy of soccer players compared to the control groups in their study of both sports performance assessment and training VR. In our study, the HVRG group obtained the most successful light suppression scores compared to other groups. Similarly, Williams et al. (2002), in the study where they compared professional and novice tennis players who were asked to react to the tennis shot on a large screen, when evaluating the system's accuracy and decision time, showed that professional players were significantly faster than novices. In another study, Mori et al. (2002) investigated reaction times for reaction task and video reaction variables in professional and novice karatists and they reported that professional karate players predicted the location of a possible attack faster than novices and that they were faster in simple reaction tests, however, the accuracy of responses was similar in both groups.

\section{Conclusion:}

Developments in sports technology play a remarkable role in the performance increase of athletes and even in achieving new records in some branches. Training with VR has become one of the common practices in recent years because it enables users to effectively analyze and improve their performance in many application areas (Cannavò et al., 2018) and in addition to team training, it is an easy alternative to individual training, which is one of the rising trends of recent years. Thanks to VR interventions that offer a virtual experience and allow direct interaction with the 
performance-oriented movements to be learned, the person is no longer passive and becomes an active part of the training process. With VR interventions, the training process can be configured, recorded and analyzed, so the performance improvements of athletes can be observed more quickly. The system also supports athletes to develop tactics by providing them with the opportunity to apply strategies and controlled feedback in controlled situations. According to our research findings, it was obtained that the individual VR program applied in addition to handball training effectively improves the balance ability and reaction time, which is extremely necessary for both handball and daily life activities.

\section{References:}

Bideau, B., Kulpa, R., Ménardais, S., Fradet, L., Multon, F., Delamarche, P. \& Arnaldi, B. (2003): Real handball goalkeeper vs. virtual handball thrower. Presence: Teleoperators Virtual Environ., 12(4):411-421.

Bideau, B., Multon, F., Kulpa, R., Fradet, L., Arnaldi, B., \& Delamarche, P. (2004): Using virtual reality to analyze links between handball thrower kinematics and goalkeeper's reactions. Neurosci. Lett., 372 (1-2) : 119-122.

Bolte, B., Zeidler, F., Bruder, G., Steinicke, F., Hinrichs, K.H., Fischer, L. \& Schorer, J. (2010): A virtual reality handball goalkeeper analysis system. Proceedings of the Joint Virtual Reality Conference of EuroVR-EGVE-VEC.Germany;1-2.

Boot, W.R., Sumner, A., Towne, T.J., Rodriguez, P. \& Anders, E.K. (2017): Applying aspects of the expert performance approach to better understand the structure of skill and mechanisms of skill acquisition in video games. Top. Cogn. Sci., 9(2):413-436.

Brault, S., Bideau, B., Craig, C. \& Kulpa, R. (2010): Balancing deceit and disguise: How to successfully fool the defender in a 1 vs. 1 situation in rugby. Human Move. Sci., 29(3):412-425.

Cannavò, A., Pratticò, F.G., Ministeri, G. \& Lamberti, F. (2018): A movement analysis system based on immersive virtual reality and wearable technology for sport training. Proceedings of the 4th International Conference on Virtual Reality, 26-31.

Chiang, I.T., Tsai, J.C. \& Chen, S.T. (2012): Using Xbox 36o kinect games on enhancing visual performance skills on institutionalized older adults with wheelchairs. Digital Game and Intelligent Toy Enhanced Learning (DIGITEL), 2012 IEEE Fourth International Conference on IEEE, 263-267.

Craig, C.M., Goulon, C., Berton, E., Rao, G. \& Fernandez, L., Bootsma, R.J. (2009). Optic variables used to judge future ball arrival position in expert and novice soccer players. Attent. Percep. Psycho., 71(3):515-522.

C, atıktas, , F., Kurt, C. \& O"zkaya, G. (2011): The effect of hand preference on the determining of the visual and auditory simple reaction times in the combat sports. Selc, uk Univer. J. Phy. Edu. Sports Sci., 13(1):109-111.

Deepa, H.S., Sirdesai, N. \& Deepa, H.S. (2016): A comparative study of auditory \& visual reaction time in table tennis players and age matched healthy controls. Indian J. Cli. Anat. Physiol., $3(4): 408-411$.

Dockx, K., Bekkers, E.M.J., Bergh, V.V., Ginis, P., Rochester, L., Hausdorff, J.M., Mirelman, A. \& Nieuwboer, A. (2016):
Virtual reality for rehabilitation in Parkinson's disease. Cochrane Database Sys. Rev, 12:CDo1076o.

Gioftsidou, A., Malliou, P., Sofokleous, P., Pafis, G. \& Beneka, A., Godolias, G. (2012): The effects of balance training on balance ability in handball players. Exerc. Qual. Life, 4(2):15-22.

Ghuntla, T.P., Mehta, H.B., Gokhale, P.A. \& Shah, C.J. (2012): A comparative study of visual reaction time in basketball players and healthy controls. Nat. J. Integr. Res. Med., 3(1):4951.

Green, S.C. \& Bavelier, D. (2006). Effect of action video game on the spatial distribution of visuospatial attention. L. Ex. Psychol.: Hum. Percep. Perform., 32(6):1465-1478.

Haibach, P.S., Collier, D.H. \& Reid, G. (2011). Motor Learning and Development. Champaign, IL: Human Kinetics, Second Edition, Pub. by: Human Kinetics, United Kingdom.

Hancock, P.A. (2009): The Future of Simulation. Vincenzi, J, Wise M, Mouloua PA: Hancock (Eds.), Human Factors Pub. by: Simulation and Training, CRC Press.

Hewett, E.T., Lindenfeld, N.T., Riccobene, V.J. \& Noyes, R.F. (1999): The effect of neuromuscular training on the incidence of

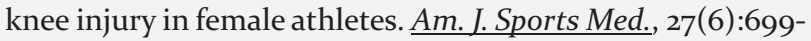
706.

Holden, M.K. (2005): Virtual environments for motor rehabilitation: review. Cyberpsychol. Behav., 8:187-211.

Horlings, C.G., Carpenter, M.G., Küng, U.M., Honegger, F., Wiederhold, B. \& Allum, J.H. (2009): Influence of virtual reality on postural stability during movements of quiet stance. Neurosci. Lett., 451:227-231.

Keshner, E.A. (2004): Virtual reality and physical rehabilitation: a new toy or a new research and rehabilitation tool? J. Neurol. Eng. Rehab., 1:8.

Khurana, M., Walia, S. \& Noohu, M.M. (2017): Study on the effectiveness of virtual reality game-based training on balance and functional performance in individuals with paraplegia. Topics Spinal Cord Injury Rehabil., 23(3):263-270. doi:10.1310/sci16-00003.

Kulpa, R., Bideau, B. \& Brault, S. (2013): Displacements in Virtual Reality for sports performance analysis pp. 299-318. Human Walking in Virtual Environments. Pub. by: Springer, .

Latham, A.J., Patston, L.M. \& Tippett, J.L. (2013): The virtual brain: 30 years of video-game play and cognitive abilities. Fron. Psychol., 4(629):1-10.

Laufer, Y., Dar, G. \& Kodesh, E. (2014): Does a wii-based exercise program enhance balance control of independently functioning older adults? A systematic review. Clin. Interv. Aging., 9:1803-1813.

Lee, K.W. \& Peng, W. (2006): Playing video games: Motives, responses, and consequences: What do we know about social and psychological effects of computer games? A Compherensive Review of the Current Literature. Pub. by: Lawrence Erlbaum Associates Publishers, New Jersey.

Mao, Y., Chen, P. \& Le Li, D.H. (2014): Virtual reality training improves balance function. Neural Reg. Res., 9(17):1628-1634.

Mauch, M. \& Kälin, X. (2011): Reliability of the ProKin Type B line system (TechnoBodyTM) balance system. Retrieved from https://www.woodway.com/sites/default/files/manuals/rel 
iability_prokinb_line_system.pdf;2011.

Michalsik, L.B., Aagaard, P. \& Madsen, K. (2013): Locomotion characteristics and match-induced impairments in physical performance in male elite team handball players. Int. J. Sports Med., 34:590-599.

Mickle, K.J., Munro, B.J. \& Steele, J.R. (2011): Gender and age affect balance performance in primary school-aged children. J. Sci. Med. Sport, 14(3):243-248.

Miles, H.C., Pop, S.R., Watt, S.J., Lawrence, G.P. \& John, N.W. (2012): A review of virtual environments for training in ball sports. Comp. Graphics, 36(6):714-726.

Mokha, R., Kaur, G. \& Sidhu, L.S. (2003): Effect of training on the reaction time of Indian female hockey players. J. Sports Med. Phys. Fitness, 153(7):208.

Mori, S., Ohtani, Y. \& Imanaka, K. (2002): Reaction times and anticipatory skills of karate athletes. Hum. Move. Sci., 21(2):213-230.

Nakamoto, H. \& Mori, S. (2008): Sport-specific decision-making in a Go/NoGo reaction task: difference among nonathletes and baseball and basketball players. Percep. Motor Skills, 106(1):163-170.

Pancar, Z., O“zdal, M., Pancar, S. \& Bic, er, M. (2016): Investigation of visual and auditory simple reaction time of 11-18 aged youth. Eu.J. Phy. Edu. SportSci., 2(4):145-152.

Porras, D.C., Siemonsma, P., Inzelberg, R., Zeilig, G. \& Plotnik, M. (2018): Advantages of virtual reality in the rehabilitation of balance and gait: systematic review. Neurol., 90(22):1017-1025.

Pourazar, M., Mirakhori, F., Hemayattalab, R. \& Bagherzadeh, F. (2017): Use of virtual reality intervention to improve reaction time in children with cerebral palsy: a randomized controlled trial. Develop. Neurorehabil., 21(8):515-520.
Rival, C., Olivier, I. \& Ceyte, H. (2003): Effects of temporal and/or spatial instructions on the speed-accuracy trade-off of pointing movements in children. Neurosci. Lett., 336(1):6569.

Romeas, T.A., Guldner, A. \& Faubert, J. (2016): 3d-multiple object tracking training task improves passing decision-making accuracy in soccer players. Psychol. Sport Exerc., 22:1-9.

Savelsbergh, G.J.P., Williams, A.M., Van der Kamp, J. \& Ward, P. (2002): Visual search, anticipation and expertise in soccer goalkeepers. J. Sports Sci., 20(3):279-287.

Taylor, M.J., McCormick, D., Shawis, T., Impson, R. \& Griff in, M. (2011): Activity-promoting gaming systems in exercise and rehabilitation.J. Rehab. Res. Dev., 48(10):1171-1186.

Williams, A.M., Ward, P., Knowles, J.M. \& Smeeton, N.J. (2002): Anticipation skill in a real-world task: Measurement, training, and transfer in tennis. J. Exp. Psychol., 8(4):259-270.

Wurm, M., Achenbach, L. \& Laver, L. (2020): Handball. In: Injury and Health Risk Management in Sports. Pub. by: Springer, Berlin, Heidelberg.

Van Diest, M., Stegenga, J., Wörtche, H.J., Verkerke, G.J., Postema, K. \& Lamoth, C.J. (2016): Exergames for unsupervised balance training at home: a pilot study in healthy older adults. Gait Posture, 44:161-167. 